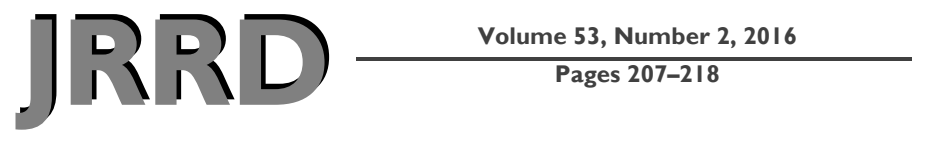

\title{
Registering a methodology for imaging and analysis of residual-limb shape after transtibial amputation
}

\author{
Alexander S. Dickinson, PhD; ${ }^{*}{ }^{*}$ Joshua W. Steer, BEng; ${ }^{1}$ Christopher J. Woods, MSc; ${ }^{1}$ Peter R. Worsley, PhD ${ }^{\mathbf{2}}$ \\ ${ }^{1}$ Bioengineering Science Research Group, Faculty of Engineering and the Environment, and ${ }^{2}$ Skin Health and Continence \\ Technologies Research Group, Faculty of Health Sciences, University of Southampton, Southampton, United Kingdom
}

\begin{abstract}
Successful prosthetic rehabilitation following lower-limb amputation depends upon a safe and comfortable socket-residual limb interface. Current practice predominantly uses a subjective, iterative process to establish socket shape, often requiring several visits to a prosthetist. This study proposes an objective methodology for residual-limb shape scanning and analysis by high-resolution, automated measurements. A 3-D printed "analog” residuum was scanned with three surface digitizers on 10 occasions. Accuracy was measured by the scan-height error between repeat analog scans and the computer-aided design (CAD) geometry and the scan versus CAD volume. Subsequently, 20 male residuum casts from ambulatory individuals with transtibial amputation were scanned by two observers, and 10 were repeat-scanned by one observer. The shape files were aligned spatially, and geometric measurements were extracted. Repeatability was evaluated by intraclass correlation, Bland-Altman analysis of scan volumes, and pairwise root-mean-square error ranges of scan area and width profiles. Submillimeter accuracy was achieved when scanning the analog shape using white light and laser scanning technologies. Scanning male residuum casts was highly repeatable within and between observers. The analysis methodology technique provides clinical researchers and prosthetists the capability to establish their own quantitative, objective, multipatient datasets. This could provide an evidence base for training, long-term follow-up, and interpatient outcome comparison, for decision support in socket design.
\end{abstract}

Key words: amputation, CAD/CAM, evidence-based prosthetics, prostheses, reliability, residual-limb shape, residuum volume, shape analysis, socket interface, surface scanning, validity.

\section{INTRODUCTION}

Advancement of prosthetic-limb technology has driven improvements in functionality and cosmetic recovery achieved in individuals with limb loss. However, in order for those with amputation to perform activities of daily living (ADLs) while wearing prostheses, maintaining appropriate human-prosthesis interface conditions to allow comfortable, stable transfer of biomechanical loads is critical. Fitting a socket to a residual limb is an iterative process, sometimes requiring several return visits to a prosthetist, typically ranging from 5 to 40 visits per year [1-2]. Residuum volume changes provide a considerable challenge to prosthetic socket fitting both in the acute and established phases of rehabilitation, reviewed extensively by Sanders and Fatone [3]. Typically, the residuum volume reduces by 17 to 35 percent in the first 6 mo postamputation in individuals with vascular disease and can stabilize after approximately $100 \mathrm{~d}$ [4-5]. Early socket

\footnotetext{
Abbreviations: ADL = activity of daily living, $\mathrm{CAD}=$ computer-aided design, CAM = computer-aided manufacturing, $\mathrm{CI}=$ confidence interval, ICC = intraclass correlation coefficient, ICP = iterative closest point, MRI = magnetic resonance imaging, RMSE = root-mean-square error.

*Address all correspondence to Alexander S. Dickinson, PhD; 5/2003, Bioengineering Science Research Group, University of Southampton, Highfield, Southampton, SO17 1BJ, United Kingdom; +44-(0)2380-595-394.

Email: alex.dickinson@soton.ac.uk http://dx.doi.org/10.1682/JRRD.2014.10.0272
} 
fitting is reported to "hasten the maturation of the residual limb as well as the adaptation of (its) form to the definitive socket" [5-6]. The residuum is not considered "mature" until 12 to 18 mo [7], and its volume still fluctuates significantly [8]. Socket adjustment and replacement come at considerable inconvenience and expense, especially where time-consuming plaster casting techniques are employed [1]. However, a well-fitting prosthesis is highly important for maximizing function during ADLs and for psychosocial rehabilitation.

Comfort is one of the most important criteria used to evaluate the quality of a prosthetic-limb fitting [9]. However, discomfort and residuum pain are common among individuals with amputations [10-12]. Poor residuumsocket fit can affect an individual's quality of life through discomfort and functional limitations, causing secondary musculoskeletal conditions such as osteoarthritis, osteoporosis, and lower back pain. These complications are more common if socket fit is not maintained because of compensatory loading of the intact limb [13]. Furthermore, incorrect socket fit can potentially lead to dermatologic problems (skin problems and contact dermatitis) [14], for example keratosis [15], and in serious cases, internal tissue strain and ischemia can lead to deep tissue injury [16]. Patients who have undergone amputation often have intrinsic risk factors such as decreased peripheral vascularity, which increase their risk of soft tissue breakdown [17]. There are also extrinsic factors: for example, soft tissues, which are not established weightbearing structures, are subjected to shear and compressive stress, increased moisture, and prolonged exposure to the chemical compounds of the prosthesis [18]. Various skin problems may develop, and their risk factors and management have been reviewed extensively in the literature [19]. Despite this, many of these individuals are sufficiently satisfied with their prosthetic limb to continue with many normal activities and are typically satisfied with prosthetist services [1].

A residuum's volume is a common clinical measurement [3] used to identify when it has stabilized such that permanent prosthesis fitting can be attempted. Volume measures are obtained by many methods, including water immersion, standardized tension tape-measure physical circumferences, photometric and anthropometric methods, and surface laser scanning. Marked differences have been observed between the methods, but for longitudinal evaluation of volume alone, reliability may be as important as validity. Laser surface scanning has been identified as the most reliable currently available method [20-
21] and is acknowledged to offer high potential accuracy. Shape is commonly assessed qualitatively as conical, cylindrical, or club-shaped (bulbous) [22-23] and may be indicated by serial circumference measurements.

Considerable advances in prosthetic socket design and manufacturing have been driven by the translation of computer-aided design (CAD)/computer-aided manufacturing (CAM) technologies since the 1980s [24-25]. Many prosthetic-limb clinical services and their componentry providers now offer socket design from digitized data. Consequently, sophisticated hardware and software systems have been developed whereby prosthetists can digitize a residual limb and conduct software-based rectification before socket fabrication. In 2007, 24 percent of prosthetic devices in the United States were reported to incorporate the use of CAD/CAM technology [26], and although the integration of this technology may have increased since, other countries and regions have been slower to adopt it. Past deterrents included the perceived cost of scanning hardware and software, variability in the accuracy achieved by central fabrication facilities [27], and concern that the technique might distance the prosthetists from the ability to exercise their fundamental tactile and experiential skill. However, the CAD/CAM process potentially allows a wealth of data to be collected for each patient and for each prosthetist's practice.

This study's objective was to present and evaluate a residuum scanning and analysis methodology that incorporates automated, objective shape characterization. An evaluation of the process validity and reproducibility is reported, quantifying the accuracy of three candidate surface scanners and the influence of inter- and intraobserver effects.

\section{METHODS}

\section{Study Design and Data Collection}

Two datasets were collected and analyzed in order to evaluate the accuracy and reliability of the cast imaging and characterization processes. To evaluate imaging accuracy, a small, representative transtibial amputation residuum "analog" was 3-D printed in cyanoacrylateinfused powder (ZPrinter 650, 3D Systems Inc; Rock Hill, South Carolina). This provided a scanning target of known geometry within the printer's tolerance margin of approximately $0.1 \mathrm{~mm}$. 
To evaluate the reliability of the cast characterization process, 20 anonymized rectified male casts of transtibial residual limbs from patients at Portsmouth Disablement Services Centre (Portsmouth, United Kingdom) were imaged over a 6 mo period (January to June 2014). Ethical permission was granted by the National Health Service ethics board and the local Research and Development service within the Hospital Trust. Suitable casts were identified by the prosthetics team at the hospital and met the following inclusion/exclusion criteria: adult individuals with transtibial amputation, at fewer than 3 mo establishment of amputation, provided with a socket-suspended prosthetic limb, and employing patellar tendon bearing or anterior slab socket rectification strategies.

\section{Methodology: Residual Limb Shape Analysis}

A MATLAB (MathWorks; Natick, Massachusetts) subroutine was written for the processing and analysis of surface scans of residual limbs, which performed the following series of operations (Figure 1). The estimated time to prepare, scan, and measure the casts are included for an experienced observer and a standard desktop computer:

- Acquisition: A residuum or its male cast is scanned, using a surface digitizer. The scan data are saved as a stl surface mesh and imported into the MATLAB workspace. Time: 60-240 s for scanning and preparation, both user intensive.

- Alignment: Using a graphical user interface, the residuum or cast shape is manually reoriented approximately so that its principal axis aligns with the global

\section{Acquire}

2. Align

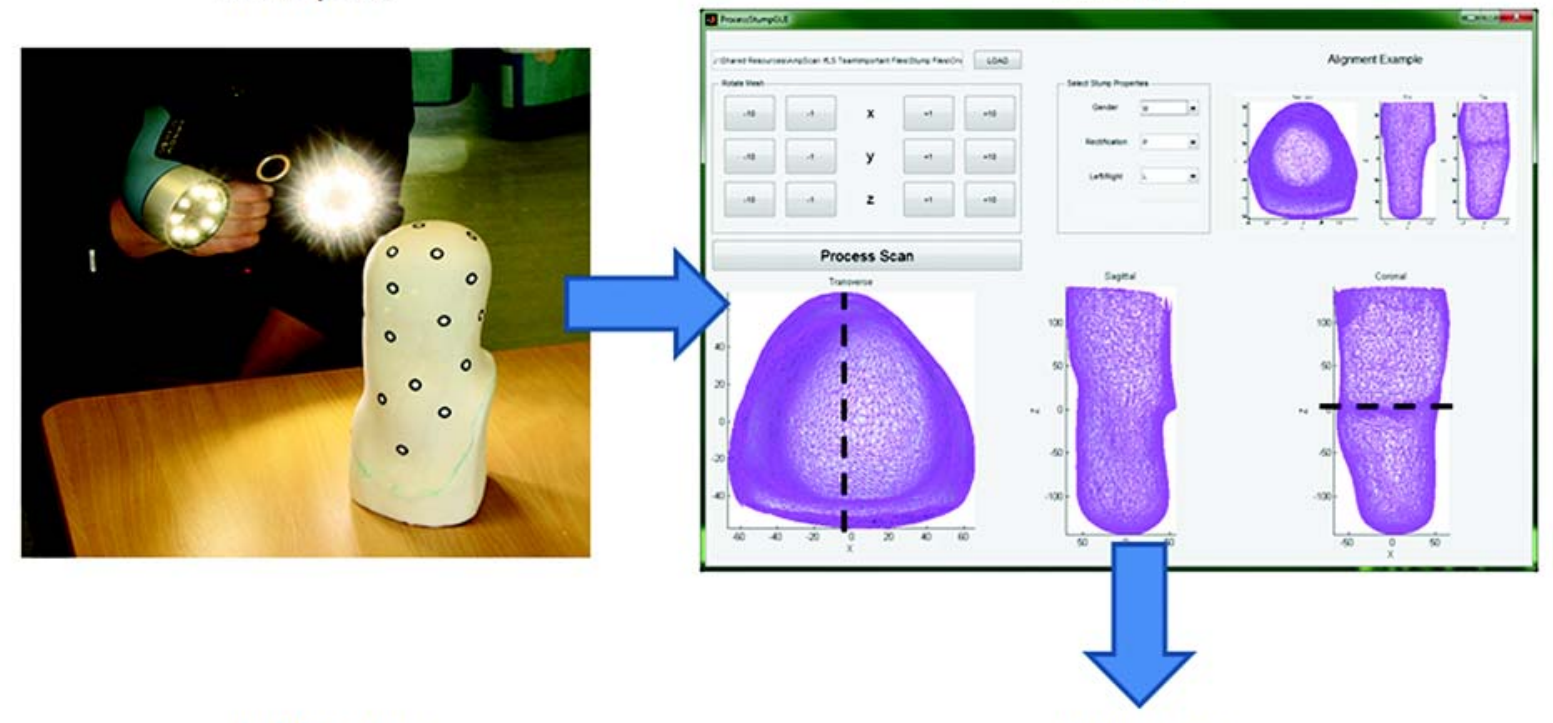

4. Measure

3. Process
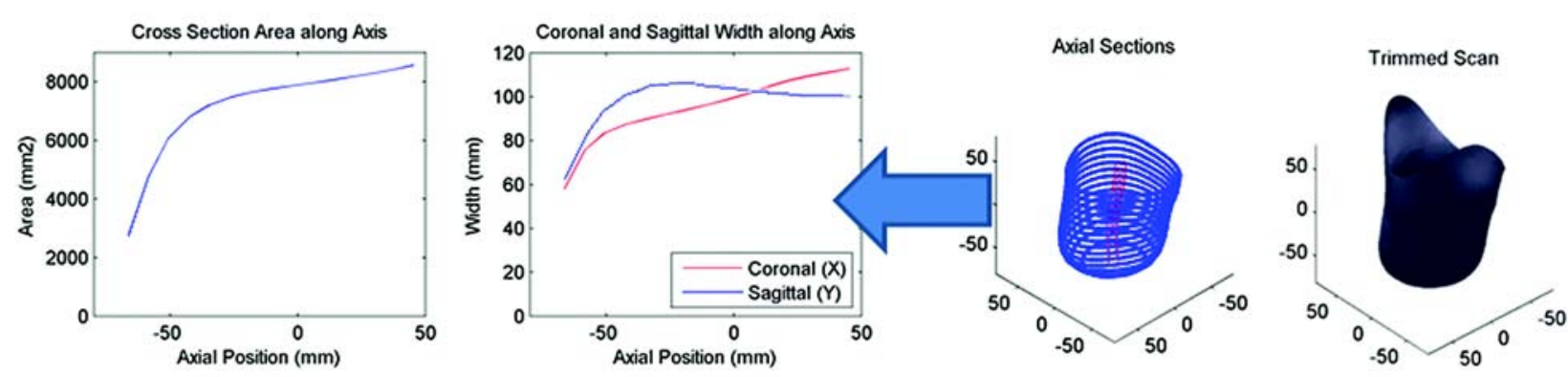

Figure 1.

Residual-limb shape analysis process. 
vertical axis in the sagittal plane and so that the patella is oriented anteriorly. In the example shown (a rectified male cast), orientation in the coronal plane is achieved by aligning the posterior trim line of the socket horizontally. If the scan were of a residual limb, orientation would be achieved by referencing markers placed over bony landmarks, such as the medial and lateral femoral epicondyles. Time: $60 \mathrm{~s}$, user intensive.

- Processing: The data are automatically processed by trimming the mesh, aligning the principal axis of the trimmed mesh with vertical in the sagittal plane, and calculating the areas and centroids of a set of crosssections at $2 \mathrm{~mm}$ intervals. Time: up to $120 \mathrm{~s}$, computer intensive.

- Measurement: Finally, the data are analyzed by automatically extracting a set of measurements, including the residuum volume and profiles of its cross-sectional area and projected widths in the sagittal and coronal planes, along the vertical axis. Time: up to $20 \mathrm{~s}$, computer intensive.

\section{Validity: Imaging Accuracy Verification}

To evaluate the accuracy and repeatability of the imaging/acquisition process, three scanners were tested: a VIUScan marker-assisted laser scanner, a Go!SCAN 3D structured white light scanner (both Creaform Inc; Lévis, Canada), and a Sense 3D markerless laser scanner (3D Systems). Each scanner was used to produce 10 repeat scans of the printed analog. Each scan mesh was imported into the MATLAB environment alongside the CAD .stl mesh used to print the analog. The scan mesh was then manually translated and rotated into approximately the same position and orientation as the CAD analog mesh and then positioned precisely using an iterative closest point (ICP) matching algorithm. Finally, the CAD analog mesh was mapped onto the scan mesh using surface registration so that the two meshes could be compared at each vertex (Figure 2).

As a measure of process error, the Euclidean distance (height) between each pair of corresponding vertices in the CAD analog and scan meshes was calculated. The mean, standard deviation, median, and maximum error of all vertices were obtained for each set of 10 scans.

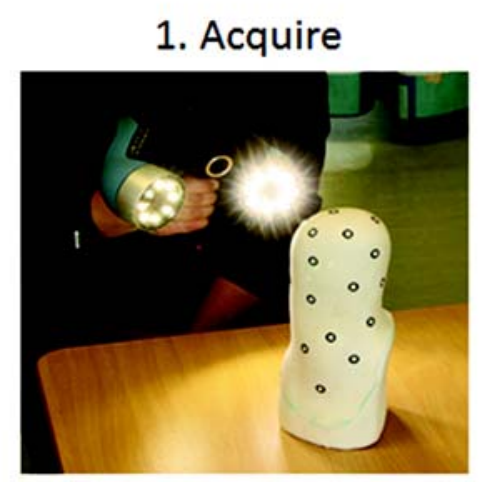

4. Rotate

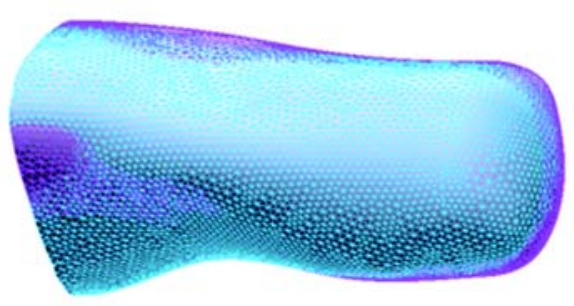

2. Import

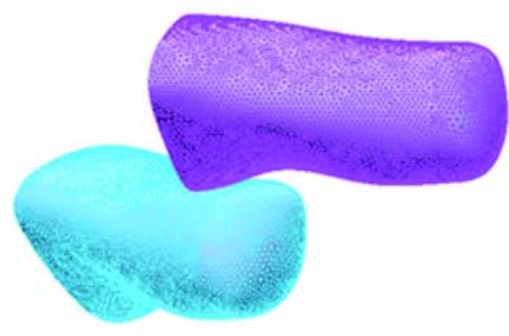

5. ICP Matching

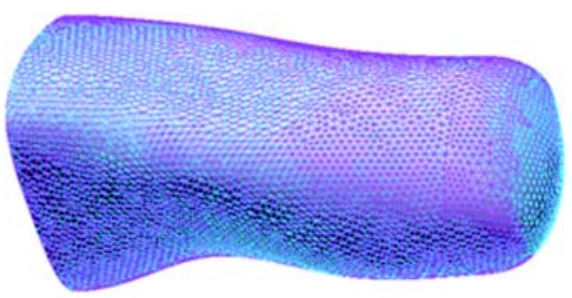

3. Translate

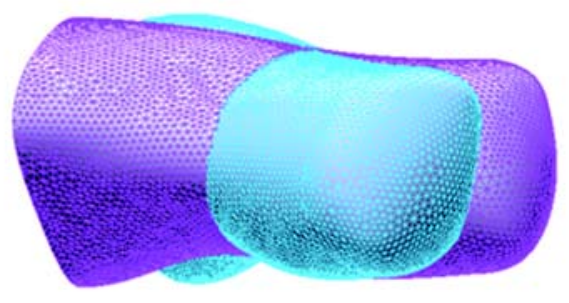

\section{Register Mesh and} Calculate Euclidean Error

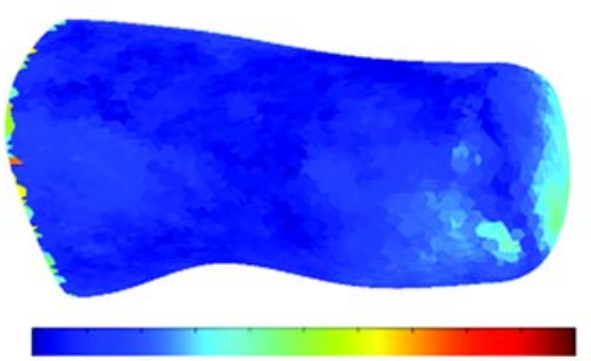

Figure 2.

Scanner accuracy verification process. ICP = interactive closest point. 


\section{Measurement Reliability}

To evaluate the reliability of scanning and measurement, a blinded inter- and intrarater characterization analysis was conducted. Using the Creaform VIUScan laser surface digitizer, repeat imaging and processing of the rectified male casts was conducted. Twenty male rectified residuum casts from individuals with transtibial amputation were imaged by two investigators within the same session (interrater assessment). Repeated measures by one observer were then taken 1 wk later on 10 of the casts (for intrarater assessment). The order in which the observers scanned the casts was randomized, and each observer independently aligned and measured the scans offsite. The reliability of the measurement process was evaluated using the following measures: total volume, cast geometry in the sagittal and coronal planes, and the area of the serial transverse sections.

Intraclass correlation coefficients (ICCs) were calculated for inter- and intrarater reliability of volumetric measures to differentiate between random and fixed errors, using respectively the $\operatorname{ICC}(3,1)$ and $\operatorname{ICC}(1,1)$ equations [28], with a 95 percent confidence interval (CI). The Bland-Altman method [29] was used to assess bias, outliers, and changes in variance with measurement size [30]. A threshold of ICC $>0.90$ was selected to represent an appropriate level of reliability for measures used for decision-making or diagnosis [31]. In addition, the rootmean-square error (RMSE) was calculated to observe the differences in the resulting geometry measures.

\section{RESULTS}

\section{Imaging Accuracy Verification}

The results of the accuracy analysis showed how the differences in scan volume error magnitude varied between scanners when comparing the data with the base- line CAD model (Table 1), with a typical scanning time for each and preparation time of applying markers to the object (VIUScan) or to the surrounding area for reference (Go!SCAN). Considering the average of 10 repeat scans, the VIUScan and Go!SCAN systems both had a surface height error magnitude up to $0.20 \mathrm{~mm}$ and $0.33 \mathrm{~mm}$, respectively, across 95 percent of the surface. The peak error was approximately 2.5 and $3.3 \mathrm{~mm}$, respectively (Figure 3). Observation of the error distribution showed that these peak errors were restricted to the scan's superior boundary, associated with the dataset cropping. The Sense system had the largest volume error and scan surface height error magnitude, which was up to $1.40 \mathrm{~mm}$ across 95 percent of the surface and peaked at $4.0 \mathrm{~mm}$.

The repeated measures of the analog cast for each scanner showed that there was high consistency of accuracy for both the VIUScan and Go!SCAN (Figure 4). However, the Sense scanner again showed more variable results and a systematic increase in error along the length.

\section{Reliability of Scanning and Measuring}

The assessment of reliability using the transtibial residuum casts revealed high levels of inter- and intrarater repeatability, with all ICCs exceeding the 0.90 threshold for clinically relevant reliability (Table 2).

Bland-Altman plots of the reliability analysis revealed that there was no effect of residuum volume on the mean difference measures either between or within observers (Figure 5), with all bar one repeated mean difference within the standard deviation limits in each case. Further analyses of the interrater differences in residuum geometry are presented in Table 3. Between-observer differences in width and area measures were all small in magnitude and highly correlated. The majority of the differences in the geometry measures were observed at the tip of the residuum cast, which represented the area of highest variability (Figure 6).

Table 1.

Scanner utility and accuracy evaluation statistics.

\begin{tabular}{|c|c|c|c|c|c|c|c|c|}
\hline \multirow[b]{2}{*}{ Scanner } & \multirow{2}{*}{$\begin{array}{c}\text { Typical } \\
\text { Preparation } \\
\text { Time (s) }\end{array}$} & \multirow{2}{*}{$\begin{array}{c}\text { Typical } \\
\text { Scanning } \\
\text { Time (s) }\end{array}$} & \multicolumn{3}{|c|}{$\begin{array}{c}\text { Surface Height Error Magnitude vs } \\
\text { Phantom }\end{array}$} & \multicolumn{3}{|c|}{ Volume Error vs Phantom } \\
\hline & & & $\begin{array}{c}\text { Mean } \pm \text { SD } \\
(\mathbf{m m})\end{array}$ & $\begin{array}{c}\text { 95th } \\
\text { Percentile } \\
\text { (mm) }\end{array}$ & $\begin{array}{l}\text { Maximum } \\
\quad(\mathbf{m m})\end{array}$ & $\begin{array}{l}\text { Mean } \pm \text { SD } \\
\quad(\mathrm{mL})\end{array}$ & $\begin{array}{l}\text { 95\% Confidence } \\
\text { Interval (mL) }\end{array}$ & $\begin{array}{l}\text { Percentage } \\
\text { Mean } \pm \text { SD }\end{array}$ \\
\hline VIUScan & 180 & 60 & $0.11 \pm 0.06$ & 0.20 & 2.51 & $-3.14 \pm 0.76$ & -4.66 to -1.62 & $-0.48 \pm 0.12$ \\
\hline Go!SCAN & 30 & 30 & $0.20 \pm 0.07$ & 0.33 & 3.28 & $-7.50 \pm 0.94$ & -9.38 to -5.62 & $-1.14 \pm 0.14$ \\
\hline Sense & N/A & 120 & $0.88 \pm 0.30$ & 1.40 & 4.04 & $+27.19 \pm 7.19$ & 12.81 to 41.57 & $+4.14 \pm 1.09$ \\
\hline
\end{tabular}


The geometry RMSE in the sagittal and coronal planes between observers ranged between 0.1 and $1.7 \mathrm{~mm}$ along the length of the casts. This resulted in low absolute error measures, with a mean absolute slice area error of $38.9 \mathrm{~mm}^{2}$ (Table 3). All geometry outputs were highly correlated between observers $(r=0.99)$.

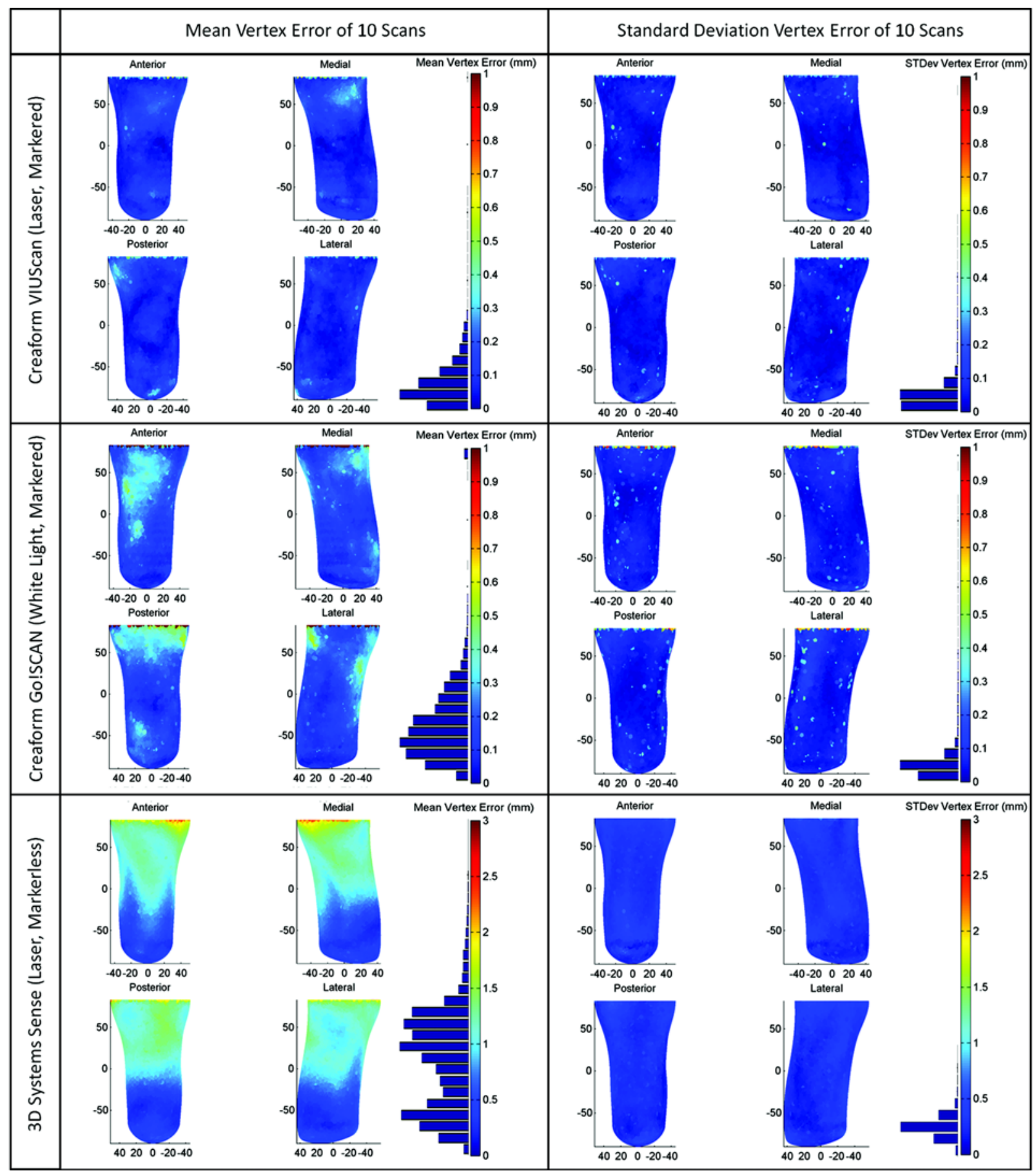

Figure 3.

Mean and standard deviation (STDev) vertex error over 10 repeat scans of analog shape compared with computer-aided design model for three evaluated scanners. Please note contour scaling. 

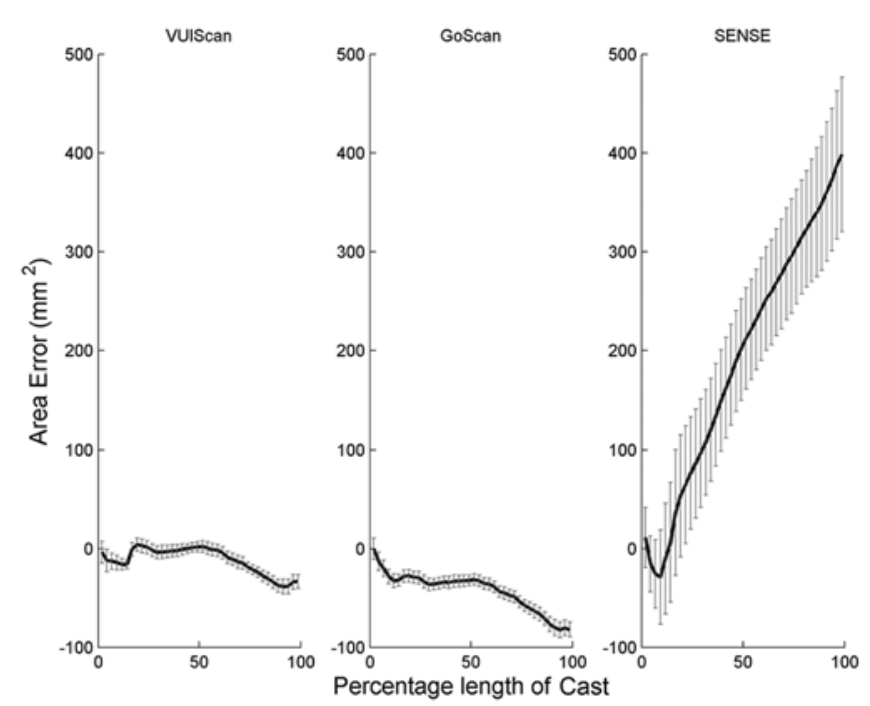

Figure 4.

Graph of mean \pm standard deviation area profile error versus computer-aided design model, over normalized length, for 3 evaluated scanners and 10 repeat scans.

\section{DISCUSSION}

This study set out to present a scan processing tool for objective characterization of the residual-limb volume and shape following transtibial amputation. The process validity was demonstrated to be within $0.5 \mathrm{~mm}$ for structured white light and marker-based laser scanners and within $1.5 \mathrm{~mm}$ for a low-cost markerless laser scanner. This corresponded to a maximum predicted (95\% CI) volume error magnitude of $4.66 \mathrm{~mL}, 9.38 \mathrm{~mL}$, and $41.57 \mathrm{~mL}$ for the three scanners, respectively. Employing the most accurate scanner, the process within-session inter- and intrarater reliability was demonstrated, with ICC coefficients and Bland-Atman error scores within the bounds required for clinical use [31].

The results of this study are comparable with previously published research that evaluated lower-limb residuum volume measurement techniques. Johanson and
Oberg evaluated the volumetric accuracy of a physical contact tracing system (ShapeMaker, Seattle Medical Systems Group; Seattle, Washington) and the CAPOD Systems laser scanner (CAPOD Systems AB; Karlskoga, Sweden) [32]. They found the systems to be capable of detecting volume changes of 2.6 and 0.8 percent, respectively, and random errors in gross volume measurement below 1.3 and 0.4 percent, respectively. McGarry and McHugh showed the physical contact TracerCAD (Ohio Willow Wood; Mt. Sterling, Ohio) CAD/CAM system had high levels of accuracy $(<2 \%)$ in gross volume and distance measures on a cylindrical analog [33] and high repeatability between four users (3\% mean volume differences) [34]. However, the same authors and colleagues showed that this consistency of measurement was not achieved in more complex transtibial residual-limb shapes [35]. Considering currently used systems, Bolt et al. used transtibial residuum models to assess five measurement methods: water immersion, dual-plane digital photography, circumferential tape measurements, digital calliper measures, and a handheld laser scanner (Omega Tracer, Ohio Willow Wood Company Inc; Mt. Sterling, Ohio) [20]. The most accurate and repeatable measures both within and between observers were obtained with the scanner, with a repeatability coefficient $(95 \% \mathrm{CI})$ of $45 \mathrm{~mL}$. Analysis of the interactions and relative contributions to volume measurement variance showed that error variance was small (6.4\%) relative to the total variance, and the interaction between method and residuum model contributed the majority of the error variance (82.6\%). Comparisons are limited because of the differing methodology of establishing reliability, but our study predicted scan volume errors below $42 \mathrm{~mL}$ for all imaging techniques. The markerless laser scanner had the highest error and was the least tolerant to inadequate lighting and object movement, but it was the least expensive of the three systems by a considerable margin and may present an opportunity for prosthetics clinics with very low funding to adopt $\mathrm{CAD}$ technologies.

Table 2.

Inter- and intrarater reliability statistics on volume measures.

\begin{tabular}{lccccc}
\hline \multicolumn{1}{c}{ Reliability Test } & ICC & 95\% Confidence Interval & F Statistic & $\boldsymbol{p}$-Value & $\begin{array}{c}\text { Pairwise Volume Difference, mL } \\
\text { (mean } \pm \text { SD) }\end{array}$ \\
\hline Interrater & 0.996 & $0.990-0.998$ & 483 & $<0.001$ & $-5.70 \pm 38.57$ \\
Intrarater & 0.998 & $0.993-0.999$ & 1,181 & $<0.001$ & $+11.90 \pm 21.70$ \\
\hline ICC = intraclass correlation coefficient, SD = standard deviation. & & & \\
\hline \hline
\end{tabular}



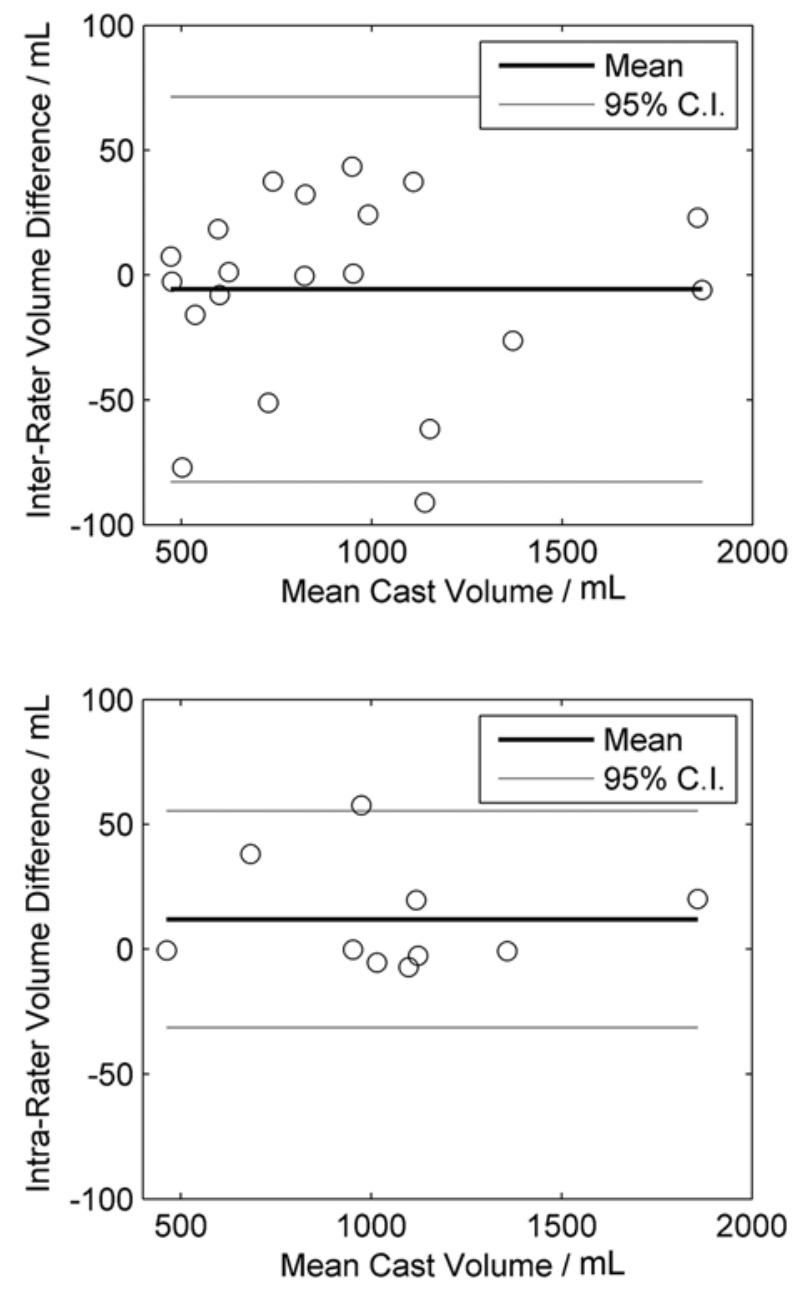

Figure 5.

Bland-Altman plot of mean scan volume difference between observers of 20 casts (left), and between repeat observations of 10 casts by one observer (right), with \pm 2 standard deviation (95\% confidence interval $[\mathrm{Cl}]$ ) limits of agreement.

Noncontact surface capture by scanning may have greater reproducibility and accuracy than the contact methods of plaster casting, tape measure circumferences, or calliper measurements. De Boer-Wilzing et al. assessed four methods of direct volume measurements of residual limbs in a transtibial amputation cohort [21], and repeatability coefficients were established by a similar method to Bolt et al. [20]. When directly measuring patient residual limbs, there was an increase in repeatability coefficients, which ranged from $129 \mathrm{~mL}$ using the scanner to $158 \mathrm{~mL}$ using digital photography. The
Table 3.

Interrater reliability statistics on area and width profile measures. Data presented as mean (range).

\begin{tabular}{lccc}
\hline Measure & $\begin{array}{c}\text { Root-Mean- } \\
\text { Squared Error }\end{array}$ & $\begin{array}{c}\text { Mean } \\
\text { Absolute Error }\end{array}$ & Correlation \\
\hline $\begin{array}{l}\text { Sagittal } \\
\text { Geometry (mm) }\end{array}$ & $0.7(0.1-1.7)$ & $0.5(0.1-1.5)$ & $0.99(0.99-1.00)$ \\
$\begin{array}{l}\text { Coronal } \\
\text { Geometry (mm) }\end{array}$ & $0.7(0.2-1.7)$ & $0.5(0.1-1.4)$ & $0.99(0.99-1.00)$ \\
Area $\left(\mathrm{mm}^{2}\right)$ & $52.0(9.7-116.9)$ & $38.9(7.4-93.3)$ & $0.99(0.99-1.00)$ \\
\hline \hline
\end{tabular}
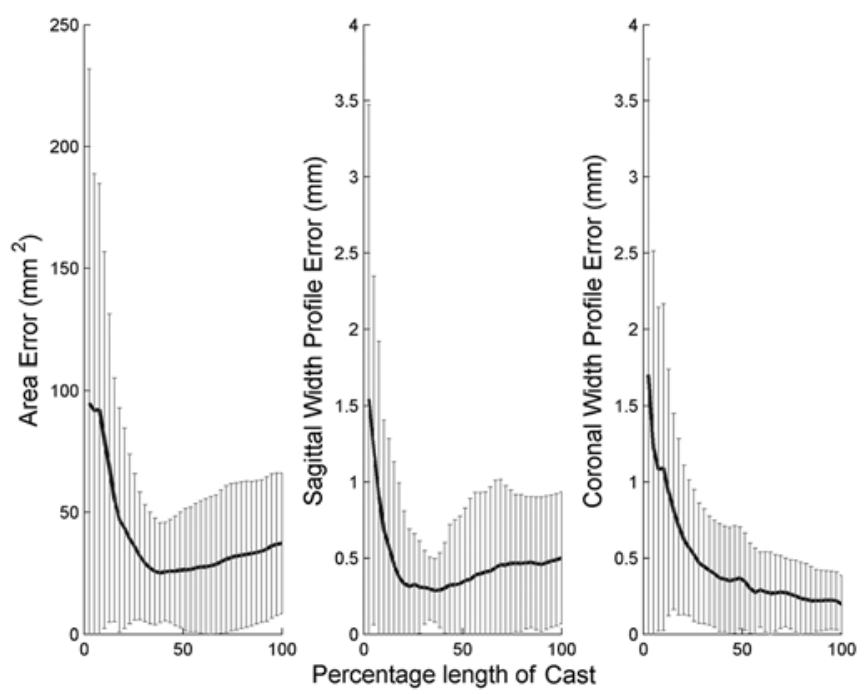

Figure 6.

Magnitude differences between observers, for 20 casts, of profile area (left) and sagittal (center) and coronal plane widths (right) versus normalized measured length.

authors also reported an elevated error variance of 11.7 percent, relative to the total variance, and in contrast to their earlier study [20], a substantial part of the error variance was explained by the method (36.3\%) and the interactions between method and patient (24.7\%) and occasion and patient (24.8\%). This shows that imaging casts or residuum analogs may not fully reflect the magnitudes or factors associated with scanning error.

An advantage of the presented methodology is that both residuum volume and geometry measures were assessed, giving a greater appreciation of how reliable the scanning modalities are in depicting the shape of residual limbs. Persson and Liedberg drew together international expert opinion to define residuum quality as a combination of desirable residuum shape, bone shape, and skin condition factors [22]. It is essential that the shape of the 
residuum is characterized accurately to provide feedback across the care pathway (surgeon, prosthetist, therapists). The presented process captured volume and shape accurately and reliably, with errors at the residuum tip alone as artifacts of the alignment process.

The technique presented should be considered as a potential augment to the follow-up of any individual with amputation and the clinician's preferred socket-fitting process. The use of scanning and comparative measurement extraction may be useful both to clinicians performing CAD/CAM socket design and those using plaster casting. The technique would assist in tracking an individual's residuum shape changes over time, where muscles atrophy and tissue stiffens with prolonged prosthetic use. Clinicians who prefer plaster casting and manual rectification may benefit from the ability to collect comparative, quantitative records of their rectifications during socket design and the potential to compare original and rectified casts. Accurate spatial alignment and dataset registration are key to enabling these comparisons. The present study has shown that residuum spatial alignment can be achieved with minimal input from a user of the developed software. Recently, Zachariah et al. and Sanders and Severance produced and demonstrated quantitative techniques to compare sockets, both to assess errors in CAD/CAM socket production and to monitor longitudinal residual-limb evaluation [36-37]. It was shown that weighted surface nor$\mathrm{mal} /$ mean absolute error algorithms performed better than ICP when aligning residuum shape models from repeat scans over a longitudinal period (for tracking changes over time). The present study employed ICP to align the very similar analog scan datasets, but as the cited studies showed, more powerful algorithms should be used when more variable scan datasets are compared.

A further advantage of the presented technique is that collecting these measures and performing the dataset registration enables direct, high-resolution interpatient residuum shape comparison. As a measure for use in clinical studies, this may provide key objective information for the highly complex relationships between residuum shape, socket design, and rehabilitation outcomes. Such information could support decision-making for surgeons when shaping the residual limb and for prosthetists during training and practice. While the authors are not aware of such research upon transtibial residual limbs, research has been conducted to develop a reference shape library of socket shapes for computer-aided socket design in transfermoral amputation [38]. However, "over time this method of using a library of reference images (to scale and make modifications to a selected image for socket design) proved to be unsuccessful and was abandoned” [39]. Extensive clinical evaluation of appropriate socket fitting to the residual limb is required before the presented process and software could be used to inform socket design, in addition to characterizing and understanding the function of the residuum's soft tissue properties.

The study is subject to several limitations. Considering clinical implementation, the reliability of the process was demonstrated for a residual-limb male cast. Only two observers were compared in the reliability study, but excellent agreement was observed based only on $1 \mathrm{hr}$ 's training by an experienced user. More variance would be expected between measurement occasions for a particular patient. As mentioned previously, while casts remain nominally identical, characterization based on scanning of the residual limb itself would be subject to fluctuations in volume that would be strongly influenced by the scanning session protocol. The time since socket doffing [8] and the degree of premeasurement activity [40] show marked effects on the limb fluid content and total volume. The practical implementation of such a residuallimb characterization would require careful observation of a standardized protocol to ensure reliability. It is likely, though, that this noncontact surface shape-capturing method would be more accurate than plaster casting or physical circumference and anthropometric measurements in capturing the shape of fleshy residual limbs [3] because the soft tissues are not distorted, especially where fine changes in topography and volume are of interest. It is also considerably faster and less expensive than magnetic resonance imaging (MRI) and its associated postprocessing.

A total volume measure is useful for residuum monitoring and evaluating size stability. This study was designed to capture profile and area change along length because these parameters will provide additional shape data to assist prosthetic socket fitting. Further information is required for full characterization of a residuum, including the residual bone geometry and the thickness, compliance, and constitution of the soft tissue layer. These data are not obtained by and cannot be inferred from surface scanning alone, but the present methodology could be applied to more data-rich volumetric imaging methods such as MRI. 


\section{CONCLUSIONS}

A residuum characterization tool for transtibial amputation was presented, and its validity and reliability were demonstrated for rectified limb casts. The proposed residuum characterization process may complement established methods of prosthetic socket fitting, overcoming the subjectivity of iterative manual approaches by providing information to assist prosthetists in exercising their skill and experience. The technique provides clinical researchers and prosthetists the capability to establish an evidence base for prosthetist training, long-term patient follow-up, and interpatient outcome comparison for decision support in socket design.

\section{ACKNOWLEDGMENTS}

\author{
Author Contributions: \\ Study concept and design: A. S. Dickinson, P. R. Worsley. \\ Acquisition of data: A. S. Dickinson, P. R. Worsley. \\ Analysis and interpretation of data: A. S. Dickinson, P. R. Worsley, \\ J. W. Steer, C. J. Woods. \\ Drafting of manuscript: A. S. Dickinson, P. R. Worsley. \\ Critical revision of manuscript for important intellectual content: \\ A. S. Dickinson, P. R. Worsley, J. W. Steer, C. J. Woods. \\ Providing final approval of the version to be published: \\ A. S. Dickinson, P. R. Worsley, J. W. Steer, C. J. Woods.
}

Financial Disclosures: The authors have declared that no competing interests exist.

Funding/Support: This material was based on work supported by the University of Southampton Institute for Life Sciences Multidisciplinary Science and Enterprise Project grant (U.K. Government Higher Education Innovation Fund), the University of Southampton's Faculty of Engineering and the Environment (EPSRC/NIHR Network grant EP/M000303/1), and the Royal Academy of Engineering (grant $\mathrm{RF} / 130)$.

Additional Contributions: The authors thank Chantel Ostler, MSc MCSP, Amputee Specialist Physiotherapist, and the prosthetics team at Portsmouth Disablement Services Centre for their assistance with obtaining ethical approval for the study and supporting patient recruitment. Access to scanning equipment was kindly provided by Chris Carter at Winchester School of Art, University of Southampton, Winchester, United Kingdom, and Chris Heal at EMCO Education Ltd, Hayling Island, United Kingdom.

Institutional Review: Institutional ethical approval for the study was granted by the University of Southampton Ethics and Research Governance Office (ERGO ref FoHS-7850) and the National Research Ethics Service (NRES/IRAS ID 135708), and the Portsmouth Hospital Trusts governance Research office gave approval to use their site for data collection (reference PHT/2014/05).

Disclaimer: The views expressed in this article are those of the authors and not an official position of the institution or funder.

\section{REFERENCES}

1. Pezzin LE, Dillingham TR, Mackenzie EJ, Ephraim P, Rossbach P. Use and satisfaction with prosthetic limb devices and related services. Arch Phys Med Rehabil. 2004;85(5):723-29. [PMID:15129395] http://dx.doi.org/10.1016/j.apmr.2003.06.002

2. Haggstrom EE, Hansson E, Hagberg K. Comparison of prosthetic costs and service between osseointegrated and conventional suspended transfemoral prostheses. Prosthet Orthot Int. 2013;37(2):152-60. [PMID:22907950] http://dx.doi.org/10.1177/0309364612454160

3. Sanders JE, Fatone S. Residual limb volume change: Systematic review of measurement and management. J Rehabil Res Dev. 2011;48(8):949-86. [PMID:22068373] http://dx.doi.org/10.1682/JRRD.2010.09.0189

4. Golbranson FL, Wirta RW, Kuncir EJ, Lieber RL, Oishi C. Volume changes occurring in postoperative below-knee residual limbs. J Rehabil Res Dev. 1988;25(2):11-18. [PMID:3361456]

5. Lilja M, Oberg T. International forum: Proper time for permanent prosthetic fitting. J Prosthet Orthot. 1997;9(2):90-95. http://dx.doi.org/10.1097/00008526-199700920-00009

6. Liedberg E, Hommerberg H, Persson BM. Tolerance of early walking with total contact among below-knee amputees - A randomized test. Prosthet Orthot Int. 1983;7(2): 91-95. [PMID:6622240]

7. Berke G. Post-operative management of the lower extremity amputee: Standards of care. Official findings of the stateof-the-science conferences \#2. J Prosthet Orthot. 2004; 16(3S):6-12.

8. Zachariah SG, Saxena R, Fergason JR, Sanders JE. Shape and volume change in the transtibial residuum over the short term: Preliminary investigation of six subjects. J Rehabil Res Dev. 2004;41(5):683-94. [PMID:15558398] http://dx.doi.org/10.1682/JRRD.2003.10.0153

9. Jia X, Zhang M, Lee WC. Load transfer mechanics between trans-tibial prosthetic socket and residual limbDynamic effects. J Biomech. 2004;37(9):1371-77. [PMID:15275844] http://dx.doi.org/10.1016/j.jbiomech.2003.12.024

10. Chan KM, Tan ES. Use of lower limb prosthesis among elderly amputees. Ann Acad Med Singapore. 1990;19(6): 811-16. [PMID:2130743]

11. Sherman RA. Utilization of prostheses among US veterans with traumatic amputation: A pilot survey. J Rehabil Res Dev. 1999;36(2):100-8. [PMID:10661526]

12. Dillingham TR, Pezzin LE, MacKenzie EJ, Burgess AR. Use and satisfaction with prosthetic devices among persons with trauma-related amputations: A long-term outcome study. Am J Phys Med Rehabil. 2001;80(8):563-71. 


\section{[PMID:11475475]}

http://dx.doi.org/10.1097/00002060-200108000-00003

13. Gailey R, Allen K, Castles J, Kucharik J, Roeder M. Review of secondary physical conditions associated with lower-limb amputation and long-term prosthesis use. J Rehabil Res Dev. 2008;45(1):15-29. [PMID:18566923] http://dx.doi.org/10.1682/JRRD.2006.11.0147

14. Lyon CC, Kulkarni J, Zimerson E, Van Ross E, Beck MH. Skin disorders in amputees. J Am Acad Dermatol. 2000; 42(3):501-7. [PMID:10688725] http://dx.doi.org/10.1016/S0190-9622(00)90227-5

15. Ibbotson SH, Simpson NB, Fyfe NC, Lawrence CM. Follicular keratoses at amputation sites. Br J Dermatol. 1994; 130(6):770-72. [PMID:8011504] http://dx.doi.org/10.1111/j.1365-2133.1994.tb03416.x

16. Bouten CV, Oomens CW, Baaijens FP, Bader DL. The etiology of pressure ulcers: Skin deep or muscle bound? Arch Phys Med Rehabil. 2003;84(4):616-19. [PMID:12690603] http://dx.doi.org/10.1053/apmr.2003.50038

17. Gist S, Tio-Matos I, Falzgraf S, Cameron S, Beebe M. Wound care in the geriatric client. Clin Interv Aging. 2009; 4:269-87. [PMID:19554098]

18. Meulenbelt HE, Geertzen JH, Dijkstra PU, Jonkman MF. Skin problems in lower limb amputees: An overview by case reports. J Eur Acad Dermatol Venereol. 2007; 21(2):147-55. [PMID:17243947]

http://dx.doi.org/10.1111/j.1468-3083.2006.01936.x

19. Levy SW. Skin problems in amputees. In: Fitzpatrick TB, editor. Dermatology in general medicine. 4th ed. New York (NY): McGraw Hill; 1993.

20. Bolt A, de Boer-Wilzing VG, Geertzen JH, Emmelot CH, Baars EC, Dijkstra PU. Variation in measurements of transtibial stump model volume: A comparison of five methods. Am J Phys Med Rehabil. 2010;89(5):376-84. [PMID:20216057] http://dx.doi.org/10.1097/PHM.0b013e3181d3ea94

21. de Boer-Wilzing VG, Bolt A, Geertzen JH, Emmelot $\mathrm{CH}$, Baars EC, Dijkstra PU. Variation in results of volume measurements of stumps of lower-limb amputees: A comparison of 4 methods. Arch Phys Med Rehabil. 2011;92(6): 941-46. [PMID:21621671]

http://dx.doi.org/10.1016/j.apmr.2011.01.007

22. Persson BM, Liedberg E. A clinical standard of stump measurement and classification in lower limb amputees. Prosthet Orthot Int. 1983;7(1):17-24. [PMID:6856447]

23. Pohjolainen T. A clinical evaluation of stumps in lower limb amputees. Prosthet Orthot Int. 1991;15(3):178-84. [PMID:1780222]

24. Saunders CG, Foort J, Bannon M, Lean D, Panych L. Computer aided design of prosthetic sockets for below-knee amputees. Prosthet Orthot Int. 1985;9(1):17-22.

[PMID:4000906]
25. Öberg K, Kofman J, Karlsson A, Lindström B, Sigblad G. The CAPOD system - A Scandinavian CAD/CAM system for prosthetic sockets. J Prosthet Orthot. 1989;1(3):139-48.

26. Whiteside SR, Allen MJ, Barringer WJ, Beiswenger WD, Brncick MD, Bulgarelli TD, Hentges CJ, Lin RS. Practice analysis of certified practitioners in the disciplines of orthotics and prosthetics. Alexandria (VA): American Board for Certification in Orthotics, Prosthetics, and Pedorthics; 2007.

27. Sanders JE, Rogers EL, Sorenson EA, Lee GS, Abrahamson DC. CAD/CAM transtibial prosthetic sockets from central fabrication facilities: How accurate are they? J Rehabil Res Dev. 2007;44(3):395-405. [PMID:18247236] http://dx.doi.org/10.1682/JRRD.2006.06.0069

28. Shrout PE, Fleiss JL. Intraclass correlations: Uses in assessing rater reliability. Psychol Bull. 1979;86(2):420-28.

[PMID:18839484] http://dx.doi.org/10.1037/0033-2909.86.2.420

29. Bland JM, Altman DG. Statistical methods for assessing agreement between two methods of clinical measurement. Lancet. 1986;1(8476):307-10. [PMID:2868172] http://dx.doi.org/10.1016/S0140-6736(86)90837-8

30. Rankin G, Stokes M. Reliability of assessment tools in rehabilitation: An illustration of appropriate statistical analyses. Clin Rehabil. 1998;12(3):187-99. [PMID:9688034] http://dx.doi.org/10.1191/026921598672178340

31. Portney LG, Watkins MP. Foundations of clinical research: Applications to practice. 3rd ed. Upper Saddle River (NJ): Prentice Hall; 2009.

32. Johansson S, Oberg T. Accuracy and precision of volumetric determinations using two commercial CAD systems for prosthetics: A technical note. J Rehabil Res Dev. 1998; 35(1):27-33. [PMID:9505250]

33. McGarry T, McHugh B. Evaluation of a contemporary CAD/CAM system. Prosthet Orthot Int. 2005;29(3):221-29. [PMID:16466152] http://dx.doi.org/10.1080/03093640500199497

34. McGarry T, McHugh B. Comparison of the results of four users of a contemporary CAD/CAM system. Prosthet Orthot Int. 2007;31(1):27-35. [PMID:17365882] http://dx.doi.org/10.1080/03093640600942101

35. McGarry T, McHugh B, Buis A, McKay G. Evaluation of the effect of shape on a contemporary CAD system. Prosthet Orthot Int. 2008;32(2):145-54. [PMID:18569882] http://dx.doi.org/10.1080/03093640802015920

36. Zachariah SG, Sorenson E, Sanders JE. A method for aligning trans-tibial residual limb shapes so as to identify regions of shape change. IEEE Trans Neur Sys Rehab Eng. 2005;13(4):551-57. [PMID:16425837] http://dx.doi.org/10.1109/TNSRE.2005.858459

37. Sanders JE, Severance MR. Assessment technique for computer-aided manufactured sockets. J Rehabil Res Dev. 
JRRD, Volume 53, Number 2, 2016

2011;48(7):763-74. [PMID:21938663]

http://dx.doi.org/10.1682/JRRD.2010.11.0213

38. Torres-Moreno R, Foort J, Morrison JB, Saunders CG. A reference shape library for computer aided socket design in above-knee prostheses. Prosthet Orthot Int. 1989;13(3): 130-39. [PMID:2608420]

39. Engsberg JR, Clynch GS, Lee AG, Allan JS, Harder JA. A CAD CAM method for custom below-knee sockets. Prosthet Orthot Int. 1992;16(3):183-88. [PMID:1491952]

40. Sanders JE, Harrison DS, Cagle JC, Myers TR, Ciol MA, Allyn KJ. Post-doffing residual limb fluid volume change in people with trans-tibial amputation. Prosthet Orthot Int. 2012;36(4):443-49. [PMID:22588848]

http://dx.doi.org/10.1177/0309364612444752
Submitted for publication October 31, 2014. Accepted in revised form June 23, 2015.

This article and any supplementary material should be cited as follows:

Dickinson AS, Steer JW, Woods CJ, Worsley PR. Registering a methodology for imaging and analysis of residuallimb shape after transtibial amputation. J Rehabil Res Dev. 2016;53(2):207-18.

http://dx.doi.org/10.1682/JRRD.2014.10.0272

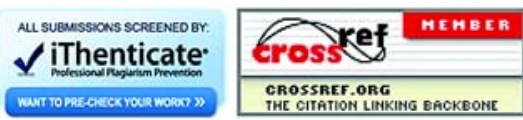

